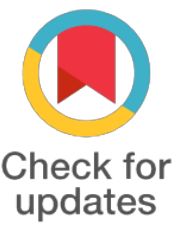

*For correspondence:

boudjelalmo@ngha.med.sa

Competing interests: The authors declare that no competing interests exist.

Received: 2017-08-07

Accepted: 2017-08-21

Published: 2017-09-05

Copyright The Author(s) 2017. This article is published with open access by BioMedPress (BMP).

This article is distributed under the terms of the Creative Commons Attribution License (CC-BY 4.0) which permits any use, distribution, and reproduction in any medium, provided the original author(s) and the source are credited.

\section{Differential expression of circadian genes in leukemia and a possible role for Sirt1 in restoring the circadian clock in chronic myeloid leukemia}

Sabhi Rahman, Al-Shaimaa Al-hallaj, , Abdullah Mashour, and Mohamed Boudjelal

King Abdullah International Medical Research Center, Ministry of National Guard Health Affairs, Riyadh, Kingdom of Saudi Arabia

\begin{abstract}
Dis-regulation of genes making up the mammalian circadian clock has been associated with different forms of cancer. This study initially aimed to address how the circadian clock genes behave over the course of treatment for both the acute and chronic forms of leukemia and whether any could be used as potential biomarkers as a read-out for therapeutic efficacy. Expression profiling for both core and peripheral clock genes revealed that the majority of clock genes are down-regulated in AML patients apart from Cry 2 which is up-regulated towards the end of treatment. A similar observation was seen in ALL patients however here, Cry2 expression came back up towards control levels upon treatment completion. In addition, all of the core clock genes are down-regulated in both chronic forms of leukemia (CML and CLL) apart from Cry2 which is not affected when the disease is diagnosed. Furthermore, the $\mathrm{NAD}(+)$ - dependent protein deacetylase Sirt 1 has been proposed to have a dual role in both control of circadian clock circuitry as well as promotion of cell survival by inhibiting apoptotic pathways in cancer. We used a pharmacological-based approach to see whether Sirtl played a role in regulating the circadian clock circuitry in both Acute and Chronic forms of leukemia. Our results suggest that interfering with Sirtl leads to a partial restoration of BMAL1 oscillation in CML patient samples. Furthermore, interfering with Sirtl activity leads to both the induction and repression of circadian clock genes in both Acute and chronic forms of leukemia and therefore makes it a potential therapeutic target to either augment existing therapies for chronic leukemia or to act as a means of facilitating chronotherapy in order to maximize both the effectiveness of existing therapies and to minimize therapy-associated toxicity.
\end{abstract}

Keywords

Funding

References 